\title{
Sensory Tuning beyond the Sensory System: An Initial Analysis of Auditory Response Properties of Neurons in the Lateral Amygdaloid Nucleus and Overlying Areas of the Striatum
}

\author{
Fabio Bordi and Joseph LeDoux \\ Center for Neural Science, New York University, New York, New York 10003
}

The lateral amygdaloid nucleus (AL) is anatomically connected with sensory processing structures in the thalamus and cortex and is believed to be critically involved in emotional processing by virtue of these connections. In order to understand further how auditory projections to AL contribute to emotional processing, acoustic response properties of single AL neurons were characterized in rats. Recordings were also made in the posterior striatum dorsal to AL. Many cells in AL and the striatum could be driven by broad-band auditory stimulation with white noise or clicks. Initial onset latencies were typically between 12 and $25 \mathrm{msec}$. Most cells also had later responses (60-150 $\mathrm{msec}$ ), and a few only had late responses. In frequency receptive field tests, different classes of cells were identified. One group had relatively clear frequency preferences. Thresholds for these relatively tuned cells tended to be somewhat higher in AL than in the striatum. Frequency preferences for AL cells were always above $10 \mathrm{kHz}$. Although most striatal cells had preferences for frequencies above $10 \mathrm{kHz}$, some cells were found with frequencies below $10 \mathrm{kHz}$ as well. A second group of acoustically responsive neurons, much more common in AL than in the striatum, showed no frequency specificity (untuned cells). These responded to a wide range of frequencies, even at intensities near threshold. A third group, found mainly in AL ( $\sim 60 \%$ of the total population of cells examined in $A L)$, exhibited rapid habituation to auditory stimuli. These tended to have high thresholds (80-100 dB). Because these cells habituated so quickly, frequency specificity could not be determined. Responses in $\mathrm{AL}$ and the striatum were compared with responses in the "specific" auditory relay nucleus of the thalamus, the ventral division of the medial geniculate body, where cells had shorter onset latencies, narrower tuning functions, and lower-intensity thresholds than cells in $A L$ and striatal areas. These findings show that cells in AL exhibit a wide range of auditory tuning properties and suggest that information processing in the amygdala might be fruitfully studied as a direct extension of processing in sensory afferent structures.

Received Oct. 10, 1991; revised Jan. 17, 1992; accepted Jan. 28, 1992.

This work was supported by U.S. Public Health Service Grants MH38774 and MH46516. We are grateful to Dr. Norman Weinberger and Mr. Casey Stengle for their help in setting up the auditory stimulation experiments, to Dr. Weinberger for his frequent advice and for providing the BRAHMS auditory histogram construction software (developed by (iabriel Hui), and to Dr. Aage Moller for his advice on earphone calibration and auditory stimulation.

Correspondence should be addressed to Joseph LeDoux, Center for Neural Science, New York University, 6 Washington Place, New York, NY 10003.

Copyright (C) 1992 Society for Neuroscience 0270-6474/92/122493-11\$05.00/0
The amygdala is one synapse removed from sensory processing areas of the thalamus (LeDoux et al., 1985, 1990a; Turner and Herkenham, 1991) and cortex (Whitlock and Nauta, 1956; Jones and Powell, 1970; Herzog and Van Hoesen, 1975; Veening, 1978; Turner et al., 1980; Ottersen, 1982; Russchen, 1982; Amaral, 1987; LeDoux et al., 1991). These connections are believed to underlie the amygdala's role as an essential structure in the neural circuitry through which sensory stimuli are endowed with emotional significance (Weiskrantz, 1956; Gloor, 1960; Geschwind, 1965; Jones and Mishkin, 1972; Mishkin and Aggleton, 1981; Rolls, 1986; LeDoux, 1987).

The close association of the amygdala with sensory processing areas of the brain suggests that amygdala neurons should be highly responsive to sensory stimuli and might display sensory tuning (receptive field) properties not altogether unlike those found in primary sensory systems. A number of studies have, in fact, shown that amygdala neurons are responsive to relatively simple sensory events (e.g., auditory tones, visual flashes, somesthetic touches) (Brown and Buchwald, 1973; Le Gal La Salle and Ben-Ari, 1981; Pascoe and Kapp, 1985; Schutze et al., 1987), as well as to complex, biologically significant stimuli (O'Keefe and Bouma, 1969; Fuster and Uyeda, 1971; Jacobs and McGinty, 1972; Sanghera et al., 1979; Ono et al., 1988; Brothers et al., 1990). However, it is not known whether responses to simple events, like pure tones, reflect frequencyspecific coding or broad tuning, nor whether responses to complex events, like species-specific calls, reflect highly specialized encoding of stimulus configurations or simple trigger stimuli embedded in complex events. Although questions about the sensory functions of an area of the brain are traditionally approached by analyzing the receptive field properties of the neurons in that area, this kind of analysis has not been performed on amygdala neurons. A sensory receptive field analysis might provide new insights into the information processing functions of amygdala neurons and might also provide new clues as to how information processing by amygdala neurons transforms sensory signals into emotional events.

The purpose of this study was to characterize auditory receptive field properties of single neurons in the lateral amygdaloid nucleus (AL) of the rat. AL was chosen because it is the major amygdaloid recipient of sensory projections (Herzog and Van Hoesen, 1975; Turner et al., 1980; Amaral, 1987; LeDoux et al., 1990a, 1991). Recordings were also made in striatal areas dorsal to AL. Auditory response properties of units in AL and the striatum (STR) were compared with those of units in the ventral division (MGv) of the medial geniculate body (MGB), the specific or "lemniscal" thalamocortical auditory relay nu- 
cleus (Morest, 1965; Calford and Webster, 1981; Calford, 1983), in order to evaluate the relationship of auditory responses of units in nonauditory areas (amygdala and STR) with units in classical auditory pathways.

\section{Materials and Methods}

Studies were conducted on male Sprague-Dawley rats $(n=20)$ weighing between 300 and $350 \mathrm{gm}$. Chloral hydrate $\left(7 \%\right.$ in $\mathrm{H}_{2} \mathrm{O}$, i.p., $420 \mathrm{mg} /$ $\mathrm{kg}$ ) was administered prior to surgery and supplemented as needed (every $1-2 \mathrm{hr}$ ) throughout the experiment. Body temperature was regulated by a heating pad.

The rats were positioned in a Kopf stereotaxic frame with blunt ear bars. Stereotaxic coordinates for AL and MGv, measured from bregma, were calculated on the basis of an atlas of the rat brain (Paxinos and Watson, 1986). The cranium was exposed, a small hole was drilled above the left $\mathrm{AL}$ or $\mathrm{MGv}$, and the dura was punctured. Three small jewelers screws were placed in the anterior portion of the skull, and a rod, attached to the stereotaxic frame, was cemented to the cranial screws with dental acrylic. This rod, used to hold the head in the stereotaxic plane, made it possible to remove one ear bar (usually the right) and replace it with a calibrated sound transmission tube for delivery of stimuli close to the typanic membrane (see below).

The stereotaxic instrument and rat were transferred to a double-wall, sound-attenuated room. A metal microelectrode (impedance, 2-5 M $\Omega$ at $1000 \mathrm{~Hz}$ ) was stereotaxically positioned about $1-1.5 \mathrm{~mm}$ dorsal to $\mathrm{AL}$ or to MGv. Neural potentials were amplified $(10,000 \times)$ by an $\mathrm{AC}$ amplifier (model WDR 420, Fintronics, Derby, CT), displayed on a dual-trace storage oscilloscope (Tektronix 5111A), and sent to a BrainWave DISCOVERY data acquisition and analysis system (BrainWave Systems, Bloomfield, CO) controlled through an AST 386 personal computer (PC). Digitized unit responses were selected for a $2: 1 \mathrm{minimal}$ signal-to-noise ratio, and those exceeding this criterion were segregated on line using the DISCOVERY algorithms. In brief, the DISCOVERY software allows the on-line sorting of single units from multiunit clusters on the basis of waveform parameters. On-line spike sorting was used to segregate obviously heterogeneous clusters in order to facilitate the on-line receptive field analysis (see below), but the final data analysis was based on off-line spike sorting performed with the Brain Wave common processing software.

Auditory stimuli (clicks, white noise, tones) were synthesized by the BrainWave Systems auditory stimulator. The auditory stimulator is integrated with the DISCOVERY software and hardware and consists of a digital signal processing (DSP) board (Texas Instruments 'C30, 33 MIPS), dual 18 -bit $\mathrm{D} / \mathrm{A}$ and 16 -bit $\mathrm{A} / \mathrm{D}$ converters, and an external dual $8 \Omega$ $250 \mathrm{~W}$ passive programmable attenuator $(127 \mathrm{~dB}$ range in $1.0 \pm 0.25$ dB steps) connected to a $200 \mathrm{~W} / \mathrm{channel}$ power amplifier (Denon POA 2400), all controlled by the AST 386 PC.

Stimuli were delivered through a Sony earphone (MDR V6), stripped of its plastic housing, and mounted securely in a stainless steel container. The earphone was separated from the front and rear internal walls of the container by rubber O-rings. The front wall of the container was tapered down to a centrally located hole $(4 \mathrm{~mm}$ diameter) in which a 3 $\mathrm{cm}$ length of stainless steel tubing ( $4 \mathrm{~mm} \mathrm{o.d.)} \mathrm{was} \mathrm{fitted} \mathrm{and} \mathrm{used} \mathrm{for}$ sound transmission. A stereotaxic ear bar was attached to the center of the exterior rear wall of the container. During the experiment, the earphone housing assembly replaced one of the ear bars that had been used to hold the animal in the stereotaxic plane during surgery (see above). The distal end of the sound transmission tube fit snugly into the ear canal, allowing the delivery of stimuli close to the tympanic membrane. The sound transmission tube was always placed in the ear contralateral to the hemisphere from which recordings were made.

The sound delivery system was calibrated using the BrainWave auditory stimulator speaker calibration procedure. The first step involved determination of the power output of the sound delivery system with respect to a reference tone ( $1 \mathrm{kHz}$ at $94 \mathrm{~dB}$ re $20 \mu \mathrm{Pa}$ ) generated by a Bruel and Kjaer (B\&K) model 4230 sound level calibrator. A condenser microphone/preamplifier (B\&K models 4133 and 2639T) was placed inside fitted opening of the sound level calibrator. The output of the microphone/preamplifier was further amplified by a custom built, lownoise, high-gain operational amplifier (op-amp), the output of which was fed into an analog input of the auditory stimulator. Through the DSP board, the PC collected 8192 samples at $163.84 \mathrm{kHz}$ and passed these values through a fast Fouricr transform (FFT) opcration to calculate the power of the reference sound. This reference power value, together with the microphone calibration curve supplied by $\mathrm{B} \& \mathrm{~K}$, allowed the conversion of additional values measured through the analog input of the auditory stimulator into absolute SPL values.

The microphone/preamplifier was then inserted into a plastic holder. The holder, placed over the distal end of the sound transmission tube, positioned the microphone at approximately the same location as the tympanic membrane with respect to the end of the sound tube during the experiment. The computer delivered 400 frequencies from $200 \mathrm{~Hz}$ to $40 \mathrm{kHz}$ (in steps of $20 \mathrm{~Hz}$ between 200 and $5000 \mathrm{~Hz}$ and in steps of $200 \mathrm{~Hz}$ above $5000 \mathrm{~Hz}$ ). For each frequency passed through the earphone, microphone, microphone preamplifier, op-amp, and auditory stimulator analog input, the computer again collected 8192 samples (at $163.84 \mathrm{kIIz}$ ) and performed an FFT operation to determine the power output for that frequency. The values were converted into SPL values (see above).

During the calibration procedure, the full output of the Denon power amplifier was attenutated by $30 \mathrm{~dB}$. The output at the reference frequency $(1 \mathrm{kHz})$ was $85 \mathrm{~dB}$, which was thus $30 \mathrm{~dB}$ below the maximal output of the system for that frequency. The calibrated outputs of other frequencies were represented as deviations from the reference frequency output. A calibration curve was produced by converting \pm deviations from the reference intensity ( $85 \mathrm{~dB}$ SPL) into absolute SPL values for each frequency. Over the range of frequencies calibrated, the calibration curve obtained varied between $100 \mathrm{~dB}$ (at $2 \mathrm{kHz}$ ) to $40 \mathrm{~dB}$ (at $22 \mathrm{kHz}$ ).

Tones and intensities used for stimulus presentations were carefully selected so as to match the maximal output and attenuation limits of the sound delivery system. The maximal output for a given frequency is the calibrated intensity value of the frequency plus the amount of attenuation used in calibration $(30 \mathrm{~dB})$. These maximal output limits allowed us to generate intensities of at least $80 \mathrm{~dB}$ for all frequencies tested, except the $22-23 \mathrm{kHz}$ range, within which we could only reach a maximum intensity of $70 \mathrm{~dB}$. The attenuation limit for a given frequency is the attenuation range of the system $(127 \mathrm{~dB})$ minus the attenutation level used during calibration $(30 \mathrm{~dB})$ minus the calibrated intensity value for that frequency. The lowest SPL possible for a frequency is then the calibrated intensity value minus the attenuation limit. These attenuation limits allowed us to reduce stimulus intensity to at least $0 \mathrm{~dB}$ SPL (and often to $-20 \mathrm{~dB}$ ) for most frequencies. Although the intensities used were calibrated with respect to the SPL scale, the intensities expressed are best viewed as relative values since we did not use a sealed sound system that was calibrated near the tympanic membrane for each animal.

The electrode was advanced from its resting position (about $1.5 \mathrm{~mm}$ above AL or MGv) until unit activity was encountered during presentation of broad-band acoustic search stimuli: white noise bursts (100 msec duration with $20 \mathrm{msec}$ rise and decay times) or clicks (500 $\mu \mathrm{sec}$ duration, with $10 \mu \mathrm{sec}$ rise and decay times). Once evoked activity was detected, multiunit clusters were segregated on line into single units or into smaller clusters using the Brain Wave DISCOVERY software. Clusters were resorted off line for purposes of data analysis (see below). If one or several isolated cells or clusters exhibited a time-locked response to the broad-band search stimuli, frequency receptive fields were assessed by delivering several different intensities of isointensity tones (10-15 constant-intensity tones varying in frequency and presented in order of ascending frequencies). The duration of each tone was $50 \mathrm{msec}$, including $10 \mathrm{msec}$ rise and decay times. Each isointensity series of tones was repeated 10 times for the purpose of histogram construction. The intensity of the first isointensity tone series was selected so as to be well above threshold. Tone series intensity was lowered in 10-20 dB steps until threshold was reached. Threshold was defined as the intensity below which the unit showed no detectable excitatory change from background on the basis of short-latency responses in histograms constructed on line and on the hasis of acoustically monitored spike activity. In most experiments, the tones were delivered at a repetition rate of one per second. In later studies we determined that slower rates (one per $5 \mathrm{sec}$ ) were useful for units that exhibited rapid habituation to auditory stimuli.

At the end of each successful recording session, two small lesions $(100$ $\mu \mathrm{A}, 8 \mathrm{sec}$ ) were made $2 \mathrm{~mm}$ apart in the dorsal-ventral plane of one track. Animals were perfused with $10 \%$ buffered formalin with potassium ferrocyanide $(5 \%)$ and potassium ferricyanide $(5 \%)$. The brains were frozen and cut on a sliding microtome ( $40 \mu \mathrm{m}$ sections), and mounted sections were stained with thionin $(0.25 \%)$. Tracks were re- 
constructed on the basis of the lesion location using a camera lucida attached to an Olympus BH2 microscope.

Multiunit activity was sorted into multiple single units off line using the BrainWave common processing software. The software allows the segregation of spikes on the basis of waveform parameters. Activity that could not be segregated into single units (or in a few cases into small clusters having identical response properties) was not analyzed.

Poststimulus time histograms were reconstructed off line (using the Macintosh-based BRAHMS software provided by Dr. N. Weinberger) after off-line spike discrimination. For each isolated unit, separate histograms were made for each intensity used for isointensity tone presentations. The histograms plotted spikes per second on the y-axis against tone frequency on the $\mathrm{x}$-axis (with each tone frequency having its own poststimulus time window). From these histograms, the characteristic frequency (CF), the frequency at which a unit had its lowest threshold (Moller, 1983), was determined (see above for definition of threshold). Tuning (frequency threshold) curves were constructed by plotting the bandwidth of excitatory responses at the threshold intensity and at intensities above threshold (in 10-20 dB increments). The sharpness of tuning was evaluated by calculating the bandwidth of the tuning curve at $10 \mathrm{~dB}$ above threshold (BW) and the Q10 statistic (CF/BW) (Calford, 1983).

\section{Results}

The main concern of this study was with unit responses in AL. However, in each experiment we recorded from units in overlying areas of the STR while driving the electrode ventrally to AL. Findings from the caudate-putamen (CPU), the globus pallidum (GP), and the amygdalostriatal transition area (AST) will therefore be presented as well. Further, cells were recorded from in the MGv (ventral division of MGB), in order to compare response properties in AL, AST, GP, and CPU with response properties in a structure of the primary auditory pathway. Since neurons in striatal areas had similar response properties, results from these areas will be considered together.

\section{Responses to broad-band acoustic stimuli}

Cells were selected for study by responsivity to broad-band acoustic search stimuli (bursts of white noise or transient clicks at 80-100 dB SPL). A total of 142 units were recorded in AL $(n=94)$ and STR $(n=48)$. The greater number of units studied in $\mathrm{AL}$ reflects the focus of this project on the amygdala rather than the rclative difficulty or ease of identifying cells, as many cells encountered in STR were not studied in detail.

Cells identified in AL and STR by broad-band acoustic stimulation either had low levels of spontaneous activity $(65 \%)$ or were not spontaneously active (35\%). The spontaneously active cells fired about once per second on the average, with the most active cells firing three to five times per second. The active cells often exhibited short bursts of spontaneous discharges interspersed with long periods (several to many seconds) of inactivity (Fig. 1).

Most cells (80\%) activated in AL and STR by broad-band stimuli responded with a transient, short-latency burst of action potentials (Fig. $2 a$ ), sometimes followed by later responses (Fig. $2 b$ ). The remaining cells either had sustained discharges ( $18 \%)$ (Fig. $2 c$ ) or offset responses (2\%) (not shown). Inhibitory responses were not usually detected because of the low rates of spontaneous discharge in these cells. Thresholds for the excitatory responses were typically in the 30-60 dB SPL range.

Cells in AL and STR typically had early onset latencies (12$25 \mathrm{msec})$. Response latencies were slightly longer in AL (15-25 $\mathrm{msec})$ than in STR $(12-18 \mathrm{msec})$. The initial short-latency responses were often followed by later responses (usually around $60-70 \mathrm{msec}$ or $100-150 \mathrm{msec}$ ). Cells with long-latency initial
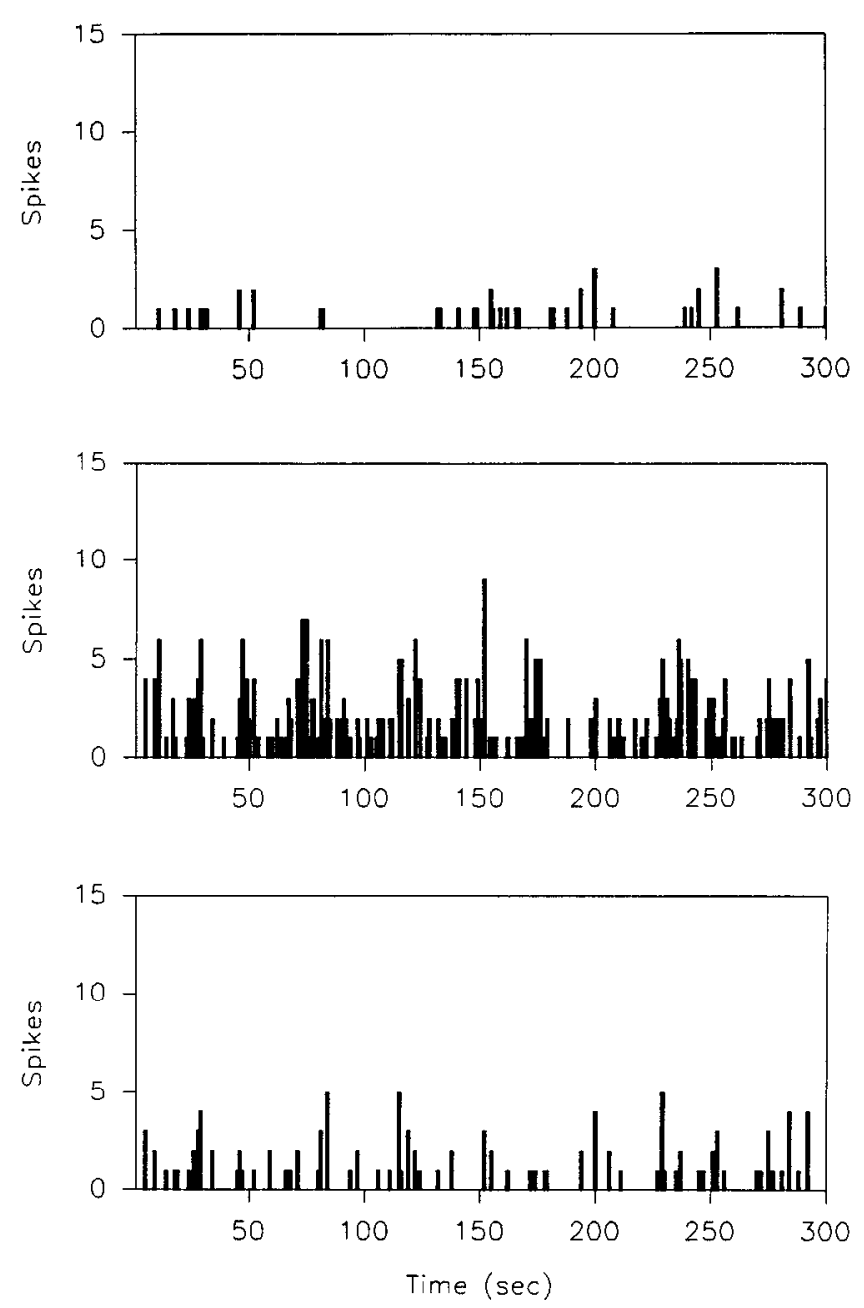

Figure 1. Spontaneous firing rates of three representative units in AL recorded continuously for $5 \mathrm{~min}$ (one sweep; bin time, $1 \mathrm{msec}$ ).

responses were more common in AL ( 25 of 94$)$ than in STR ( 3 of 48 ).

Some acoustically responsive cells in $\mathrm{AL}(41 \%)$ and most in STR $(94 \%)$ were easily and consistently driven by repetitions of acoustic search stimuli (Fig. 3). In AL 35 of the 45 units and in STR 35 of the 36 units that responded consistently had early onset latencies (12-25 msec).

A large subset of units recorded in AL (59\%) rapidly habituated to repeated presentations of broad-band search stimuli (Fig. 3). These units only fired in response to the first two to five repetitions of the stimulus and thereafter were unresponsive. A change in stimulus intensity sometimes revived the cell's responsivity. Rapidly habituating units in AL usually required high-intensity stimulation $(80-100 \mathrm{~dB})$ of white noise or clicks to produce any response. Many $(69.3 \%)$ of these habituating units exhibited short-latency responses $(<25 \mathrm{msec})$, but others $(26.7 \%)$ only responded with long latencies $(60-150 \mathrm{msec})$ (Fig. 3 ). When both short- and long-latency responses were evoked from habituating cells, the shorter-latency responses tended to be less consistent across stimulus repetitions. In contrast, longerlatency responses tended to remain over more repetitions and to have lower thresholds. Thus, as the intensity of the stimulus was lowered, the shorter-latency responses dropped out 10-20 $\mathrm{dB}$ before the longer latency responses. Only two rapidly ha- 
a

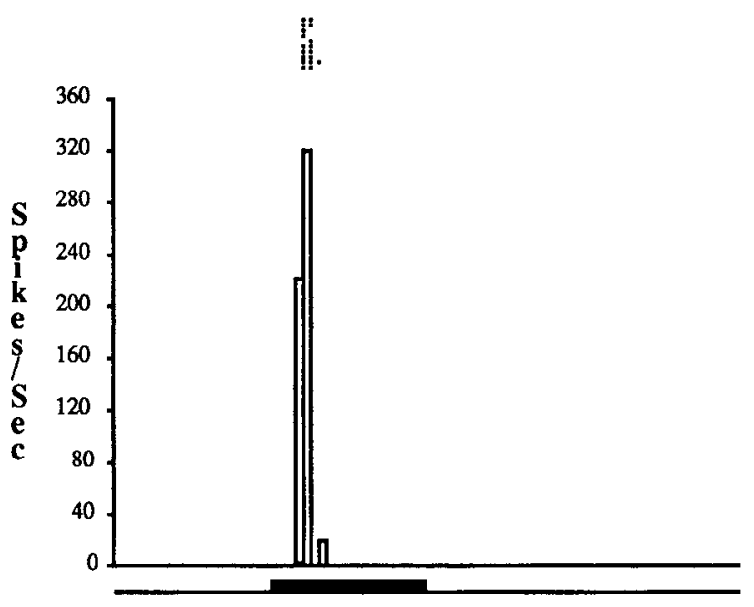

b

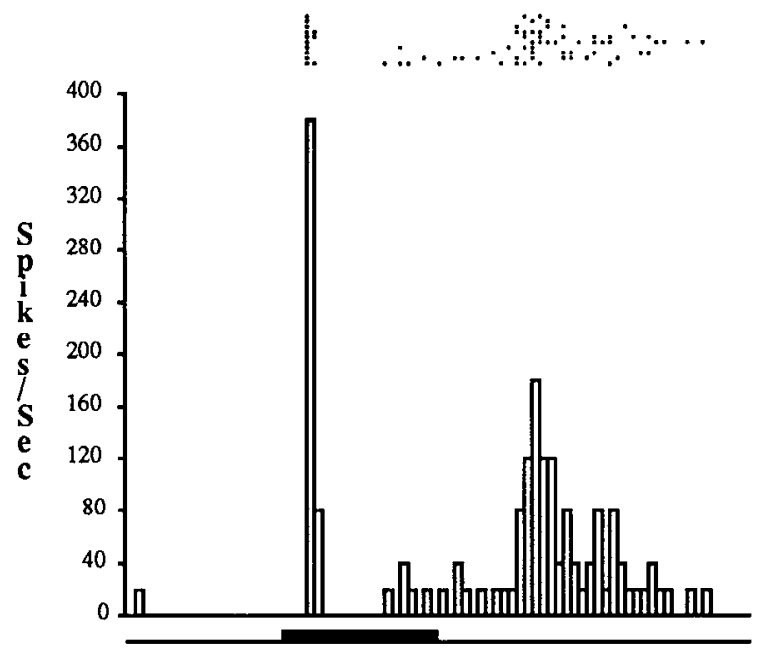

c

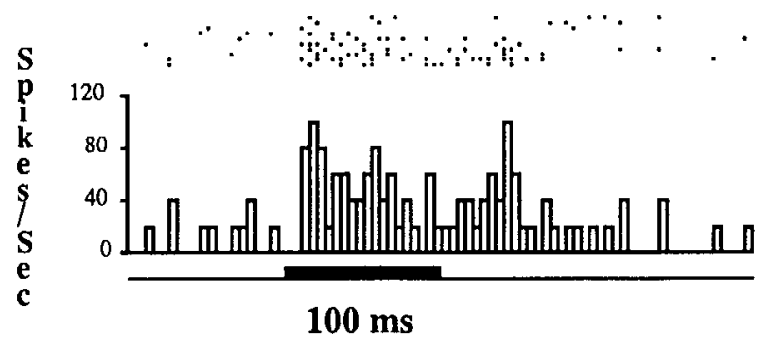

Figure 2. Typical responses of units in the $\mathrm{AL}$ and overlying areas of the STR to broad-band auditory stimulation (white noise, $80 \mathrm{~dB}$ SPL, $100 \mathrm{msec} ; 10 \mathrm{sweeps} ; 5 \mathrm{msec}$ bin time). $a$. Transient response; $b$, transient response followed by later response; $c$, sustained response. Poststimulus time histograms summating responses over the 10 trails are shown, with the stimulus period marked by the solid bar underneath each histogram. Above each histogram, raster plots illustrate the temporal distribution of spikes for each trial, with the first trial plotted on the bottom row.

biluating units were seen in STR, and these had onset latencies $>100 \mathrm{msec}$.

\section{Frequency receptive field properties}

Frequency receptive field determinations (see Materials and Methods) were made for 35 units in AL and 19 in STR. Additionally, receptive fields were determined for 7 units in MGv.

Lateral nucleus of the amygdala. AL units could be classified into two groups on the basis of frequency receptive field properties: relatively tuned cells $(n=10)$ and untuned cells $(n=25)$. Relatively tuned cells exhibited a preference for a specific frequency or frequency range. Although these cells typically responded to many frequencies when tested at high intensity levels, the range of responsive frequencies narrowed as intensity approached threshold levels. Relatively tuned cells in AL all had CFs above $10 \mathrm{kHz}$ (Fig. 4). For some relatively tuned cells in $\mathrm{AL}$ the frequency range responded to at intensities near threshold was fairly narrow. Although others responded to a wider range of frequencies, these were classified as relatively tuned because they had a clear preference for a frequency range, as contrasted to the untuned cells described below that responded to more or less the entire frequency spectrum. For the group of relatively tuned cells, the excitatory bandwidth (the distance in $\mathrm{kHz}$. between the highest and lowest frequency producing excitatory responses at $10 \mathrm{~dB}$ above threshold) was $10.5 \pm 1.4$ $\mathrm{kHz}$ on average (range, $6-18 \mathrm{kHz}$ ) (Fig. 5). The Q10 value for the relatively tuned cells was $2.1 \pm 0.4$ (range, 1.1-4.1) (Fig. 6). The four cells with the sharpest tuning (Q10 values between 2.2 and 4.1) had CFs above $16 \mathrm{kHz}$ (with three of the four having CFs between 25 and $30 \mathrm{kHz}$ ). The average threshold was $28 \pm$ $7.7 \mathrm{~dB}$ (range, -10 to $70 \mathrm{~dB}$ ) (Fig. 7). Latencies, determined from responses to broad-band stimulation, fell into two groups. Six of the relatively tuned cells responded with short initial onset latencies $(15-25 \mathrm{msec})$, while the other four had long initial onset latency responses (about $60 \mathrm{msec}$ ). Relatively tuned cells with short-latency responses were all in the dorsal part of $\mathrm{AL}$, and those with longer latencies were more common in the ventral part (Fig. 8).

Untuned cells $(n=25)$ were acoustically responsive but showed no obvious frequency preferences. Even at intensities near threshold, these cells tended to respond over a wide range of frequencies; in some instances responses were present over the entire spectrum tested, and in other instances responses were evoked by multiple, fairly wide ranges of discontinuous frequencies. These cells responded with onset latencies (determined from responses to broad-band stimulation) of either 15$25 \mathrm{msec}(n=18)$ or $>60 \mathrm{msec}(n=7)$ (Fig. 8) and had an average threshold of $37.6 \pm 4.1 \mathrm{~dB}$ (range, 0-80 dB) (Fig. 7). Untuned cells were more common in the ventral AL than the dorsal AL (Fig. 8). The excitatory bandwidth and Q10 values could not be computed since these cells did not have an obvious CF.

Responses to a series of isointensity tones could not be assessed in a third group of AL cells (rapidly habituating cells; $n$ $=49$ ) because they exhibited rapid habituation to repetitive stimulation, even when the series of stimuli involved unique frequencies, as in the isointensity series used. In the later studies we found that lengthening the interstimulus interval from 1 to $5 \mathrm{sec}$ allowed us to collect some data on the frequency responses of the rapidly habituating cells. Rapidly habituating cells tested in this way showed little tendency for frequency preferences.

Striatum. Most (14 of 19) cells in STR tended to prefer particular frequencies or a narrow range of frequencies (relatively tuned cells). Relatively tuned cells in STR had CFs more evenly distributed across the frequency spectrum tested than relatively tuned cells in AL. The cells had a frequency bandwidth of 8.8 $\pm 1.1 \mathrm{kHz}$ (range, $4-18 \mathrm{kHz}$ ) at $10 \mathrm{~dB}$ above threshold (Fig. 5) and had a Q10 of $2.3 \pm 0.9$ (range, 1.1-4.0) (Fig. 6). Average threshold for these cells was around $10 \pm 4.3 \mathrm{~dB}$ SPL (Fig. 7). Initial spike latency was between 12 and $20 \mathrm{msec}$ (Fig. 8). In two instances, two peaks of frequency sensitivity were present 
Consistently driven units with short latency responses

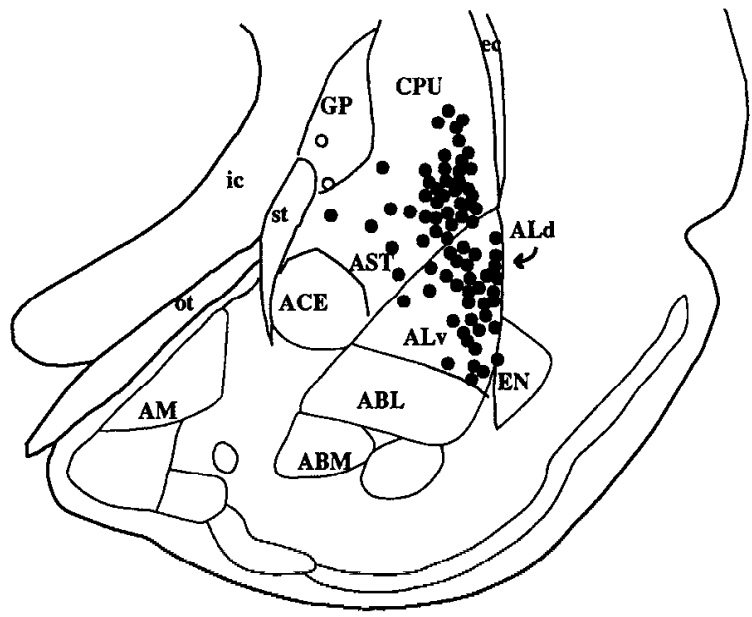

Habituating units with short latency responses

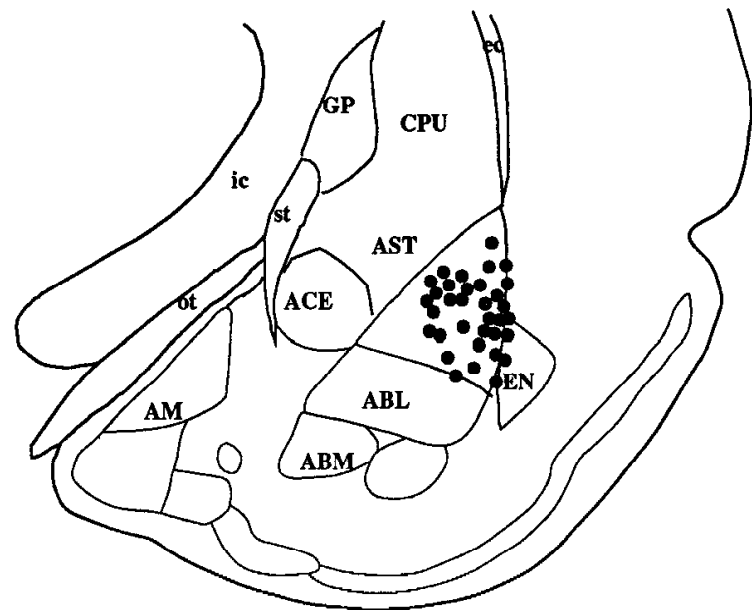

\section{Consistently driven units with long latency responses}

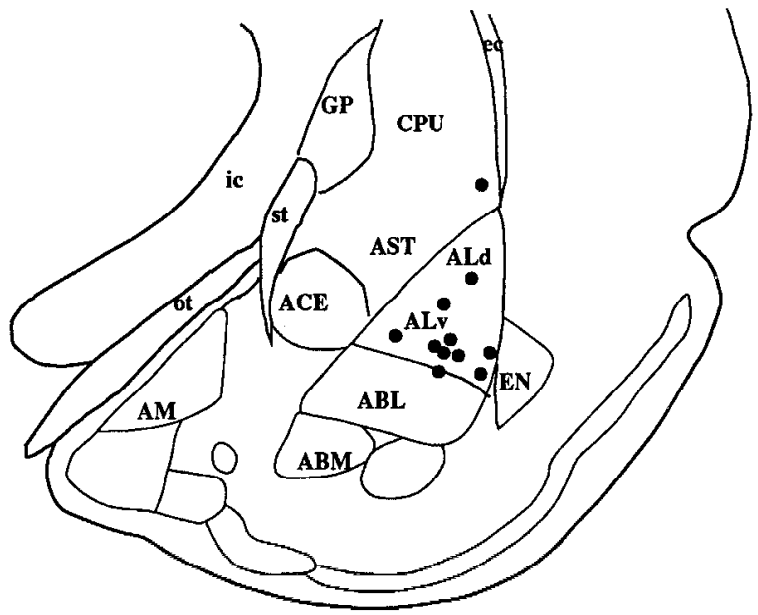

Habituating units with long latency responses

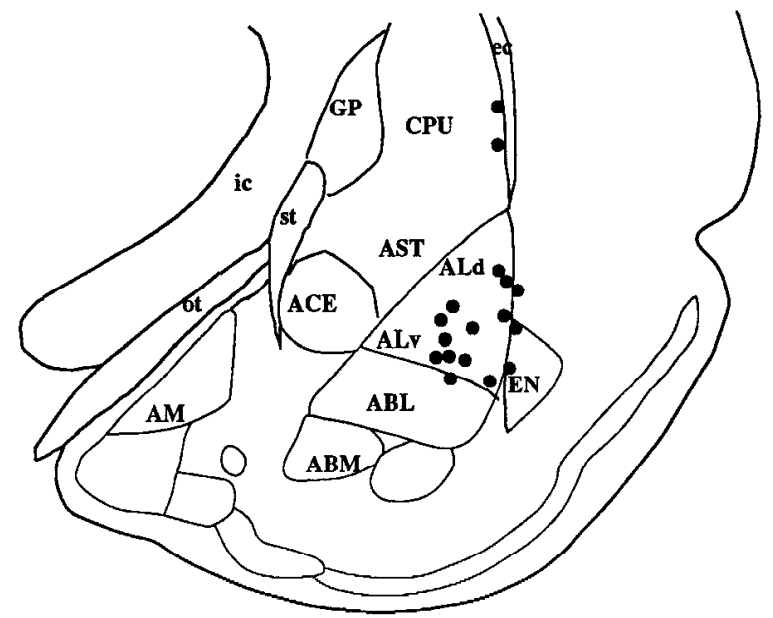

Figure 3. Anatomical map showing the locations of different classes of units responsive to broad-band auditory stimuli (white noise, $80 \mathrm{~dB}$ SPL, $100 \mathrm{msec}$ ) in the AL and overlying areas of the STR. Cells were differentiated on the basis of response latency (early, 12-25 msec; late, 60-150 msec) and response consistency (consistent units responded to repeated stimuli; habituating units only responded to initial presentations). Open circle, intermediate response latency ( $30-40 \mathrm{msec}) ; A B L$, basolateral nucleus of the amygdala; $A B M$, basomedial nucleus of the amygdala; $A C E$, central nucleus of the amygdala; $A L d$, lateral nucleus of the amygdala, dorsal division; $A L v$, lateral nucleus of the amygdala, ventral division; $A M$, medial nucleus of the amygdala; $A S T$, amygdalostriatal transistion area; $C P U$, caudate-putamen; $e c$, external capsule; $E N$, endopiriform nucleus; $G P$, globus pallidus; $i c$, internal capsule; ot, optic tract; $s t$, stria terminalis.

in a single unit (Fig. 9). The five untuned cells in STR responded to many frequencies, even at low stimulus intensities. Untuned cells had a threshold of $44.0 \pm 8.2 \mathrm{~dB}$. Their latencies were either short ( $12-20 \mathrm{msec} ; n=2)$, intermediate (30-40 msec; $n$ $=2$ ), or long ( $>60 \mathrm{msec} ; n=1$ ).

Ventral division of the medial geniculate body. Auditory responses of units in AL and STR were compared with responses obtained from the ventral division of the MGv. Cells in MGv, the specific or lemniscal thalamocortical relay nucleus in the auditory system (Morest, 1975; Calford and Aitkin, 1983; Winer and Morest, 1983; Redies et al., 1989), have short-latency responses to low-intensity stimuli and are narrowly tuned (Calford and Webster, 1981; Calford, 1983). MGv cells thus offer a useful point of reference for interpreting responses in $\mathrm{AL}$ and STR.

Twenty cells were identified in MGv in response to broadband auditory stimulation. All cells responded with short initial onset latencies $(7-12 \mathrm{msec})$ and some also had longer-latency responses $(>100 \mathrm{msec})$. Most had onset responses, though a few had sustained responses. Frequency receptive fields were examined for seven of the MGv cells selected more or less at random from the population identified. For all seven cells, the early onset responses had strong frequency preferences at low stimulus intensities. CFs were seen across the frequency spectrum, but $\mathrm{CFs}$ above $10 \mathrm{kHz}$ were more commonly encountered than $\mathrm{CFs}$ below $10 \mathrm{kHz}$ (Fig. 10). The frequency bandwidth at $10 \mathrm{~dB}$ above threshold was $3.1 \pm 1.2 \mathrm{kHz}$ (range, $2-5 \mathrm{kHz}$ ) (Fig. 5 ), and the Q10 values were $4.7 \pm 1.1$ on average (range, 2.0 9.0) (Fig. 6). Intensity thresholds were around $-14 \pm 4 \mathrm{~dB}$ SPL (Fig. 7). Frequency specificity was lacking in the long-latency responses $(>100 \mathrm{msec})$.

\section{Discussion}

The purpose of the present study was to provide an initial characterization of acoustic response properties of neurons in the rat $\mathrm{AL}$, a structure implicated in emotional functions by way of its anatomical connections with acoustic processing areas in 
Figure 4. Tuning (frequency threshold) curves for nine relatively tuned neurons located in AL. Tuning curves were constructed by plotting the responsive frequency range for intensities at and above threshold (in $10-20 \mathrm{~dB}$ steps). The frequency (or frequency range) with the lowest threshold was identified as the CF.
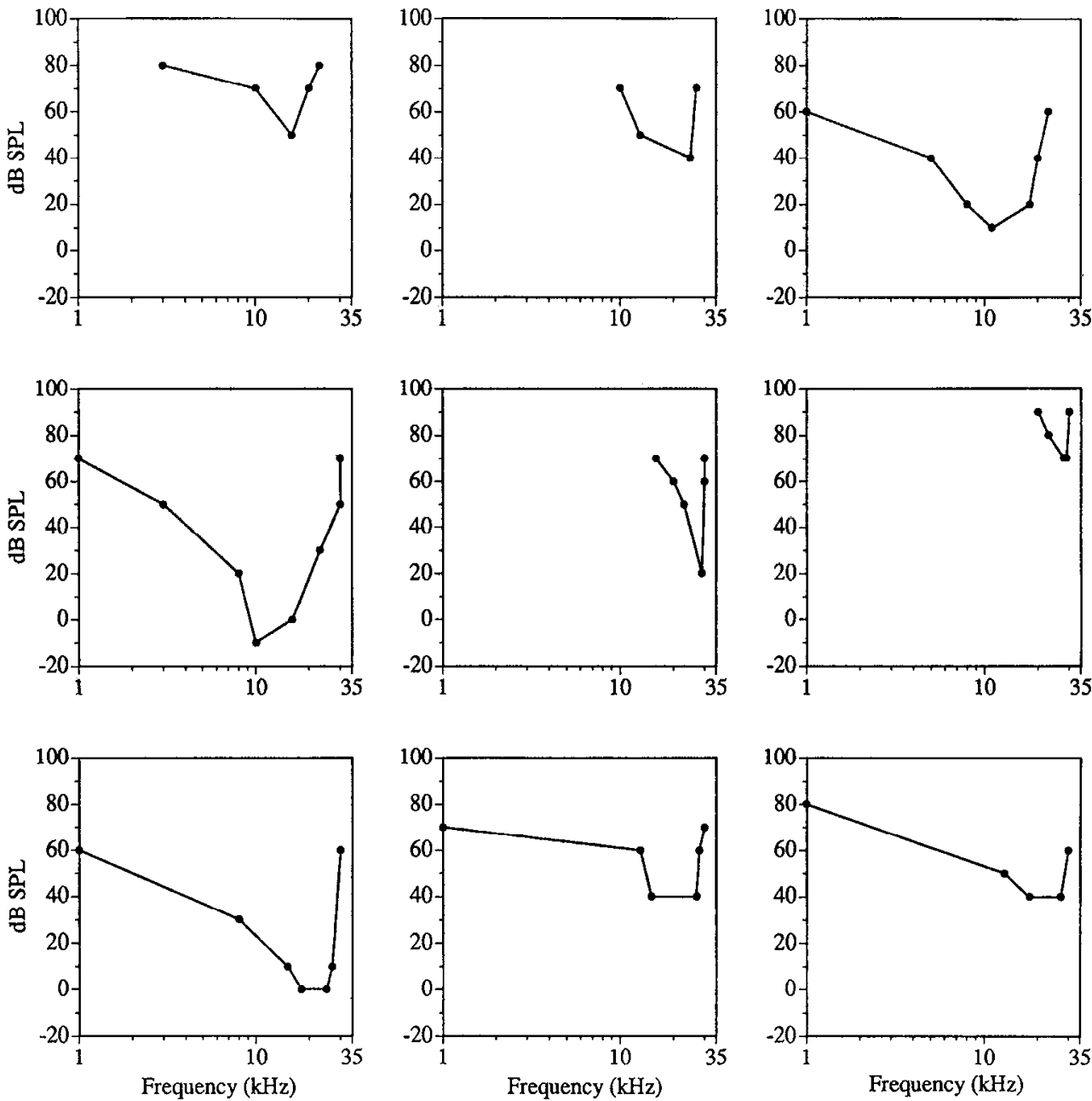

the thalamus and neocortex (see introductory remarks). Our results show that many neurons in $\mathrm{AL}$, as well as neurons in overlying areas of the STR (CPU, AST, GP), are responsive both to broad-band acoustic stimuli and to pure tones. The sensory response characteristics of these neurons have important implications for understanding the sensory basis of information processing functions of these areas.

Amygdala and striatal areas are not traditionally viewed as sensory processing structures. Recordings of auditory evoked responses from these areas thus need to be compared against some auditory standard. For this purpose, we have chosen the $\mathrm{MGv}$, the specific or lemniscal thalamocortical relay nucleus in the auditory system. Studies of cats have shown that cells in MGv exhibit short-latency, low-threshold, frequency-specific responses to acoustic stimuli (Calford and Webster, 1981; Calford, 1983). Our findings in rat are in good agreement with findings from cats. Cells in rat $\mathrm{MGv}$ responded with onset latencies of 7-12 msec to pure tones. The cells could be consistently activated by repetitive acoustic stimulation with broadband stimuli or tones. Threshold in response to tones was around $-14 \mathrm{~dB}$ SPL (this should be viewed as a relative threshold measure since we did not calibrate inside the ear canal of each animal). The cells had CFs distributed across the frequency spectrum tested (1-30 kHz), although high-frequency cells (cells with CFs above $10 \mathrm{kHz}$ ) were most common. BW (bandwidth of excitatory responses at $10 \mathrm{~dB}$ above threshold) was always restricted to a narrow range of frequencics. BW was slightly wider than that reported for the cochlear nucleus of the rat (Moller, 1983), suggesting convergence in the frequency domain between the cochlear nucleus and the MGv.

Cells in AL differed from MGv cells in several important ways. First, in response to white noisc, most cells in AL tended to give initial onset responses in the $15-25 \mathrm{msec}$ range. This is roughly twice the latency seen in MGv cells (7-12 msec).

Second, many cells in AL (59\%) were of the rapidly habituating type. They responded to the first few presentations of white noise but were subsequently unresponsive unless long interstimulus intervals and high stimulus intensities were used. Such cells were not encountered in MGv.

Third, other cells in AL (about 30\%) responded repeatedly to auditory stimuli but showed no frequency preferences. These cells responded indiscriminantly to a wide range of stimuli, often giving responses across the frequency spectrum, even at low stimulus intensities. These auditory responsive, but untuned, cells were not seen in MGv but have been described in the medial division of MGB (MGm) of the cat (e.g., Calford, 1983), a division known to project to AL (LeDoux et al., 1990a).

Fourth, a small group of cells $(n=10$, about $11 \%$ ) exhibitcd clear preferences for restricted frequencies. The $\mathrm{BW}$ and the Q10 (CF/BW) of these cells were on average wider than that of MGv cells. AL cells thus would in general appear to receive auditory information that has converged more across the fre- 


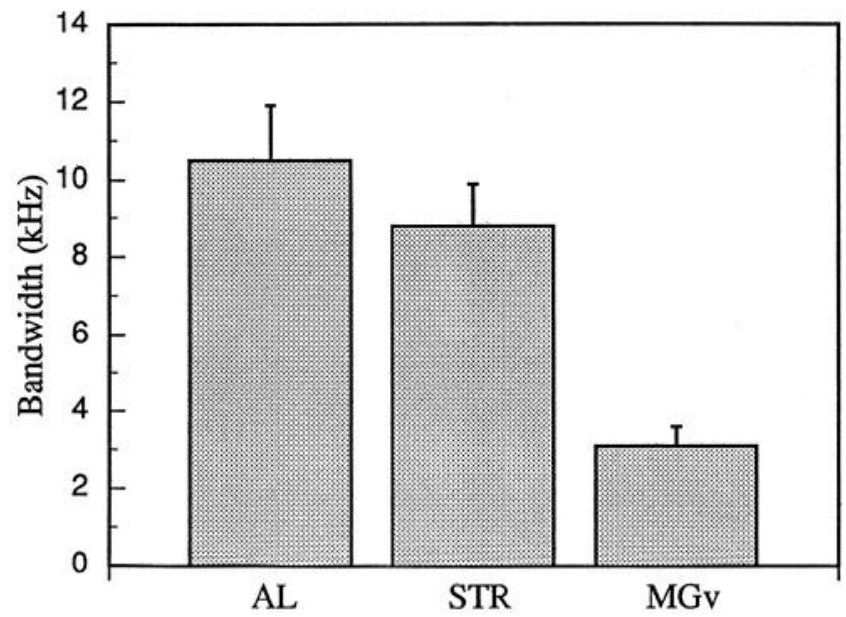

Figure 5. Frequency bandwidth (the distance in $\mathrm{kHz}$ between the highest and lowest frequency producing excitatory responses) at $10 \mathrm{~dB}$ above threshold for AL, STR, and MGv cells. AL and STR were both significantly different from MGv (one-way ANOVA: $F(2,30)=8.38, p<$ 0.001 ; post hoc $t$ tests comparing AL to MGv and STR to MGv were significant at the 0.01 level). Values shown are mean $\pm \mathrm{SE}$.

quency domain than MGv cells. Cells in the more medial areas of the MGB, the areas containing the thalamoamygdala projection neurons, in fact tend to exhibit broader tuning than cells in the MGv (Calford, 1983), thus possibly accounting for the difference we observed between AL and MGv. However, some cells in the medial areas of the auditory thalamus also show narrow tuning (Calford, 1983), which may account for the fact that the more sharply tuned AL cells had Q10 values that overlapped with the lower values obtained from MGv. AL neurons thus exhibit a wide range of tuning, from very broad to fairly narrow.

Fifth, the CFs of AL cells were all in the high end of the frequency spectrum (above $10 \mathrm{kHz}$ ), and three of cells with the most restricted frequency responses had CFs between 25 and $30 \mathrm{kHz}$. Although cells with high CFs were also predominant in $\mathrm{MGv}$, cells with $\mathrm{CFs}$ below $10 \mathrm{kHz}$ were also found. The concentration of high frequencies in these structures may be related to the the importance frequencies in this range for rodents as distress signals (see below).

Sixth, regardless of other characteristics, AL cells tended to have high thresholds in response to tones. For example, cells in MGv had thresholds around $-14 \mathrm{~dB}$, whereas the tuned and untuned cells in AL had average thresholds of 28 and $38 \mathrm{~dB}$, respectively (with the range extending over $70 \mathrm{~dB}$ for both cell types). These differences, while best viewed as relative differences rather than absolute SPL values, illustrate a large difference in threshold between AL and MGv cells.

Auditory responses were somewhat different in the dorsal and ventral parts of AL. Relatively tuned cells tended to be located in the dorsal rather than the ventral $\mathrm{AL}$, whereas untuned and rapidly habituating cells tended to be more common in the ventral AL. Further, for a given cell type (i.e., relatively tuned, untuned, habituating), latencies tended to be somewhat shorter in the dorsal than ventral AL. These distinctions may be related to differences in the anatomical inputs to the dorsal and ventral AL. For example, projections from the auditory thalamus terminate more extensively in the dorsal than ventral AL (Fig. 3 in LeDoux et al., 1990b; Turner and Herkenham, 1991). Since

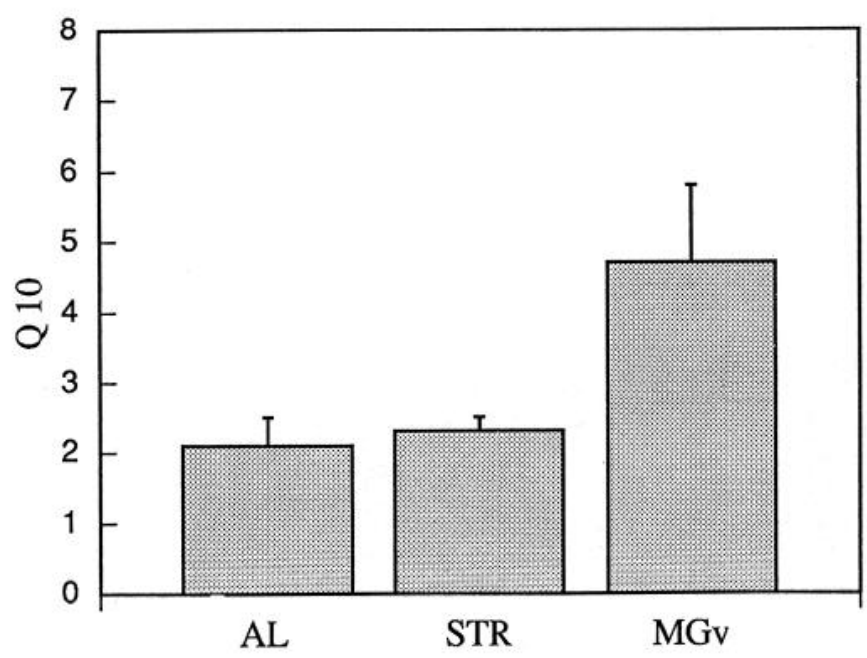

Figure 6. Q10 values for cells in AL, STR, and MGv. Q10 values were only calculated for cells with tuning properties (i.e., all MGv cells and relatively tuned cells in AL and STR). Q10 values were calculated as CF/BW (see Materials and Methods). AL and STR were both significantly different from MGv (one-way ANOVA: $F(2,30)=6.75, p<$ 0.004 ; post hoc $t$ tests comparing AL to MGv and STR to MGv were significant at the 0.05 level). Values shown are mean \pm SE.

the ventral AL appears to receive projections from the dorsal AL (J. LeDoux, unpublished observations with Phaseolus vulgaris leucoagglutinin), the response properties of ventral AL cells may in part reflect convergence of inputs from several dorsal AL cells with somewhat more specific response properties. Corticoamygdala projections have not been reported to terminate more extensively in the dorsal AL.

Cells in STR shared many characteristics with cells in the dorsal AL, but also differed in some respects. First, striatal cells seldom exhibited rapid habituation; though somewhat less common in the dorsal than the ventral $\mathrm{AL}$, habituating cells were more common in dorsal AL than in striatal areas. Second, stri-

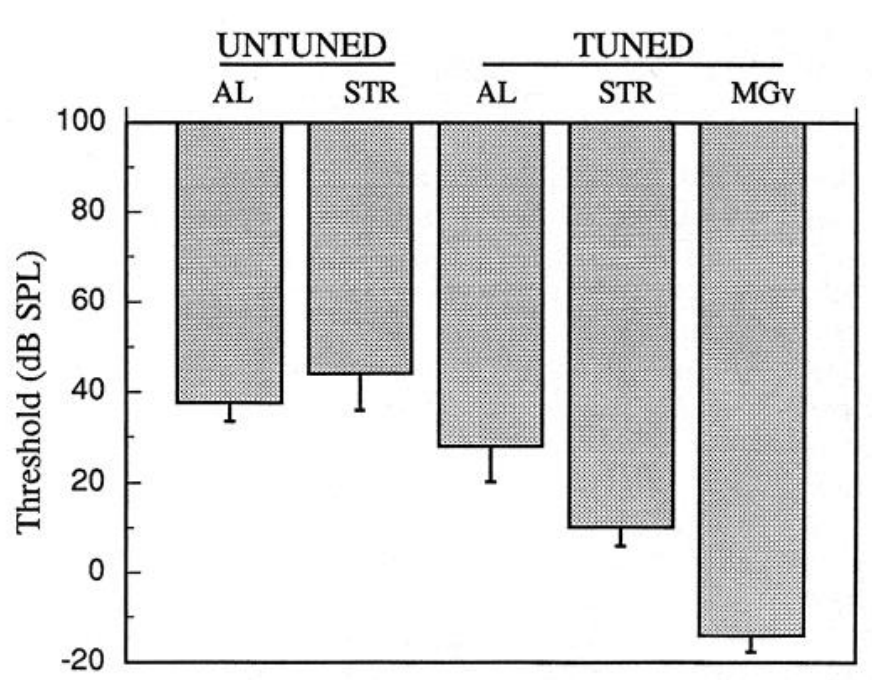

Figure 7. Threshold intensity (the lowest stimulus intensity producing any auditory response) for cells in AL, STR, and MGv. Tuned AL and STR cells were both significantly different from MGv (one-way ANOVA: $F(4,56)=13.3, p<0.001$; post hoc $t$ tests comparing tuned AL to MGv and tuned STR to MGv were significant at the 0.01 level). Values shown are mean $\pm \mathrm{SE}$. 


\section{Relatively tuned units with short latency}

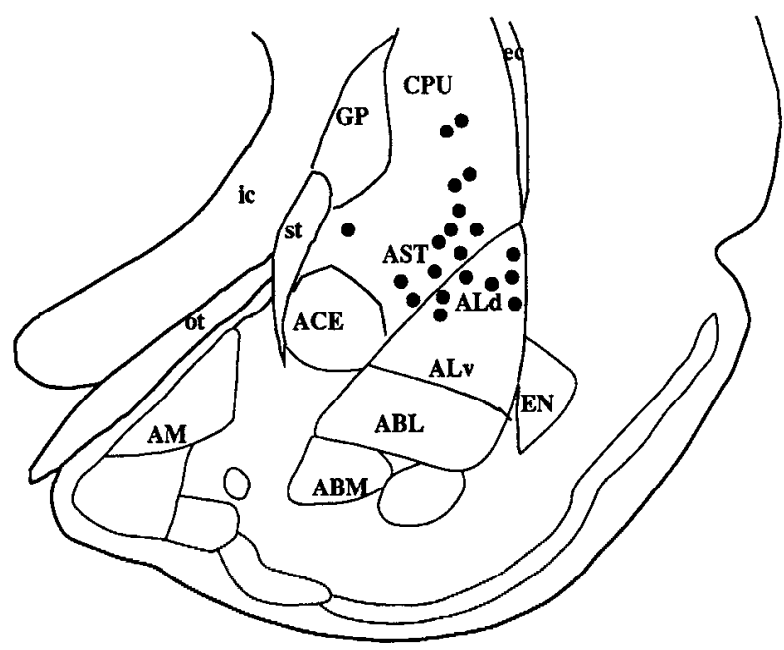

Untuned units with short latency

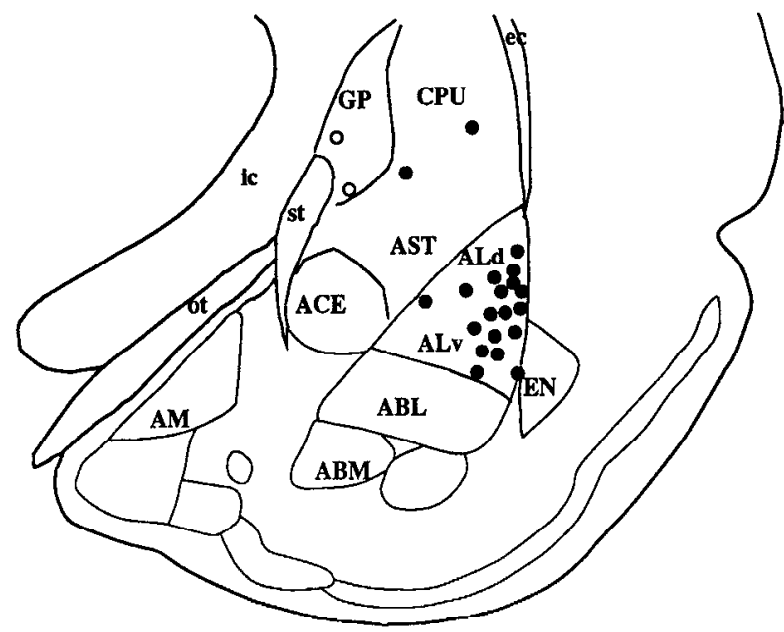

Relatively tuned units with long latency

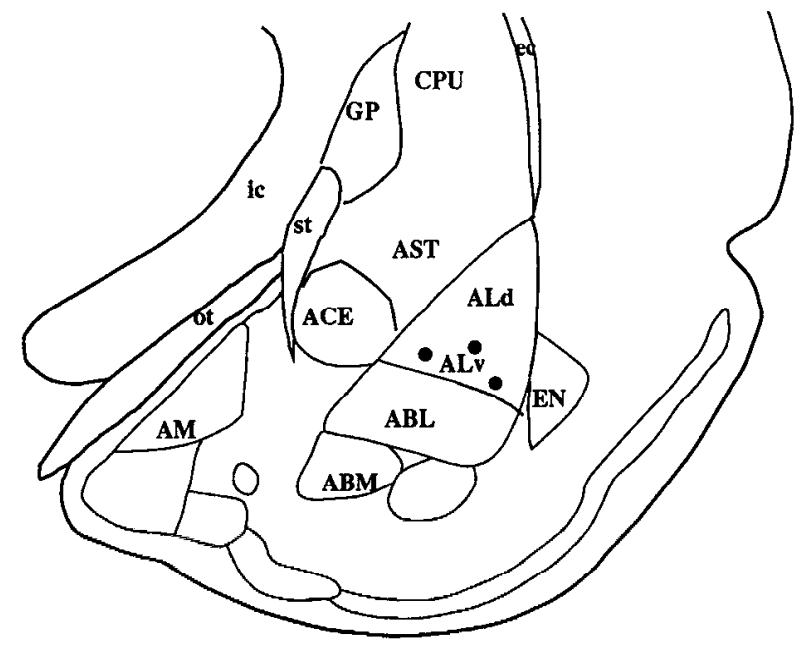

Untuned units with long latency

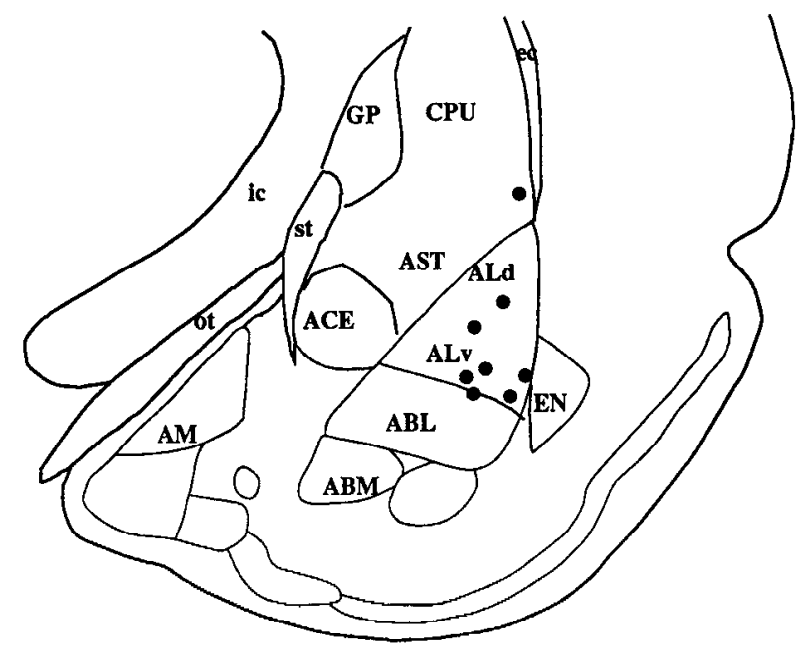

Figure 8. Anatomical map showing the location of tuned and untuned units in AL and STR. Cells in these categories are further distinguished on the basis of their response latencies (early, 12-25 msec; late, $60-150 \mathrm{msec}$ ). Latencies were obtained in response to broad-band stimulation (white noise, $80 \mathrm{~dB}, 100 \mathrm{msec}$ ). See Figure 3 for abbreviations.

atal cells had CFs more evenly distributed across the frequency range (frequencies below $10 \mathrm{kHz}$ were found in the striatum). Third, striatal cells had somewhat lower auditory thresholds and shorter latencies than dorsal AL cells. These differences between striatal and $\mathrm{AL}$ cells may be related to differences in anatomical connections. The posterior striatal areas recorded from receive the thalamic auditory inputs mainly from the $\mathrm{MGm}$, whereas most of the thalamic auditory projections to AL come from the posterior intralaminar nucleus (PIN) (LeDoux et al., 1990a). Electrical stimulation studies have also shown that units in STR respond slightly faster than AL units to stimulation of the auditory thalamus (Clugnet et al., 1990), suggesting that the MGm-STR projection may have a somewhat faster conduction velocity than the PIN-AL projection. Also, striatal areas receive projections from primary auditory cortex, as well as from auditory association cortex (Jones and Powell, 1970; Kemp and Powell, 1970; Yeterian and Van Hoesen, 1978), whereas the amygdala only receives inputs from the later stages of sensory processing (Jones and Powell, 1970; Herzog and Van Hoesen,
1975; Turner et al., 1980; Amaral, 1987). Thus, both thalamic and cortical pathways to the amygdala appear to reach the striatum earlier than the amygdala.

It is possible that the earliest responses $(12-20 \mathrm{msec})$ to auditory stimuli are mediated by direct thalamic projections to AL, AST, and CPU (LeDoux et al., 1990a). Thalamic (MGB) cells respond to acoustic stimuli within 7-10 $\mathrm{msec}$, and stimulation of MGR produces unit responses in AI and STR in 4$8 \mathrm{msec}$. These latencies suggest a transmission time from stimulus onset to AL and STR of about $11-18 \mathrm{msec}$, which is roughly what we observed. Also, since the thalamoamygdala projection arises from cells MGm and PIN, where narrowly tuned, broadly tuned, and untuned acoustically responsive cells are found but broad and untuned cells predominate (Calford and Webster, 1981; Calford and Aitkin, 1983; Bordi and LeDoux, unpublished observations on PIN), the receptive field properties of cells in AL and STR are consistent with those of the thalamic cells of origin of the projection and therefore with direct thalamoamygdala transmission. However, there are multiple, poly- 

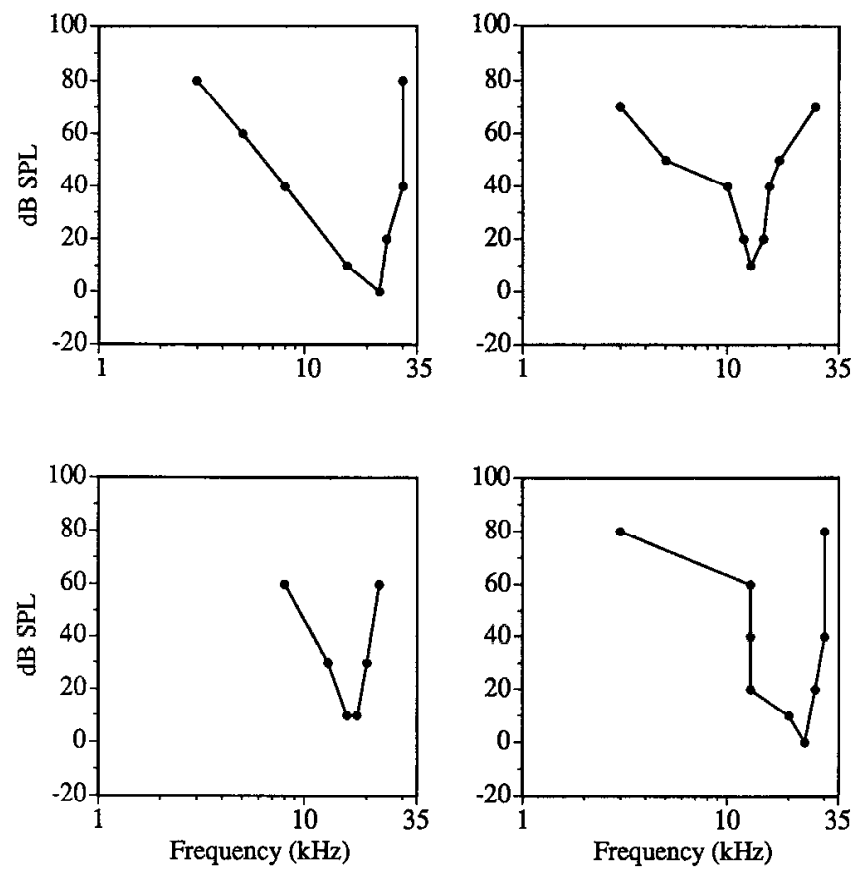

synaptic routes through auditory cortex for thalamocorticoamygdala transmission in the rat (LeDoux et al., 1991; L. M. Romanski and J. E. LeDoux, unpublished observations), as in other species (e.g., Jones and Powell, 1970; Herzog and Van Hoesen, 1975; Turner et al., 1980; Amaral, 1987), and these pathways could conccivably account for responses that are too late to be accounted for by direct thalamoamygdala transmission (responses around 20-25 msec). Responses are also seen in AL around $60 \mathrm{msec}$ and again between 100 and $150 \mathrm{msec}$. These long-latency responses are likely to reflect longer transmission loops. For example, cells in MGv exhibit long-latency auditory responses that are untuned, in contrast to the tuned, shortlatency responses, suggesting that acoustic signals might be
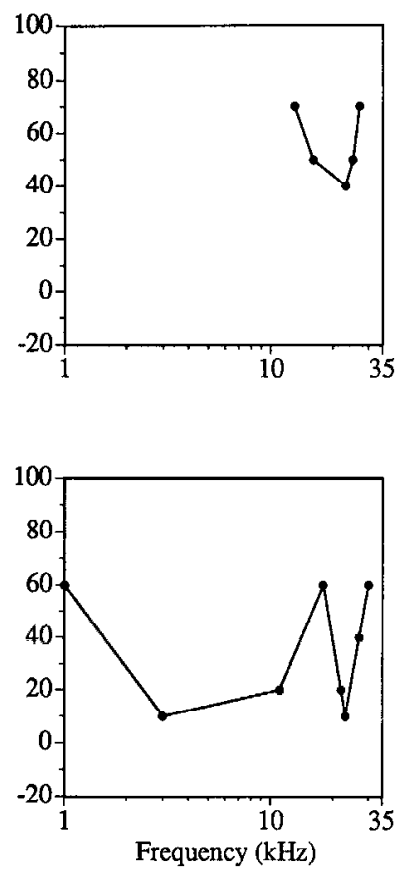

Figure 9. Tuning (frequency threshold) curves for six relatively tuned neurons located in STR. See Figure 4 for explanation of tuning curve construction. Compare with tuning curves from $\mathrm{AL}$ (Fig. 4) and MGv (Fig. 10).

transmitted from thalamus to cortex and back to thalamus before being transmitted to amygdala (either directly or by way of cortex) and might lose tuning specificity in the process. Also, AL receives projections from portions of the hippocampal formation and the frontal cortex (Veening, 1978; Aggleton et al, 1980; Ottersen, 1982; Russchen, 1982). These areas receive auditory signals over highly convergent, polysynaptic, corticocortical transmission routes (Pandya and Kuypers, 1969; Jones and Powell, 1970; Van Hoesen, 1982; Amaral, 1987). Our observation that the late acoustic responses were in general broadly tuned if not untuned is consistent with transmission over channels where extensive frequency convergence has taken place.

Studies of unit activity in the amygdala have tended to focus
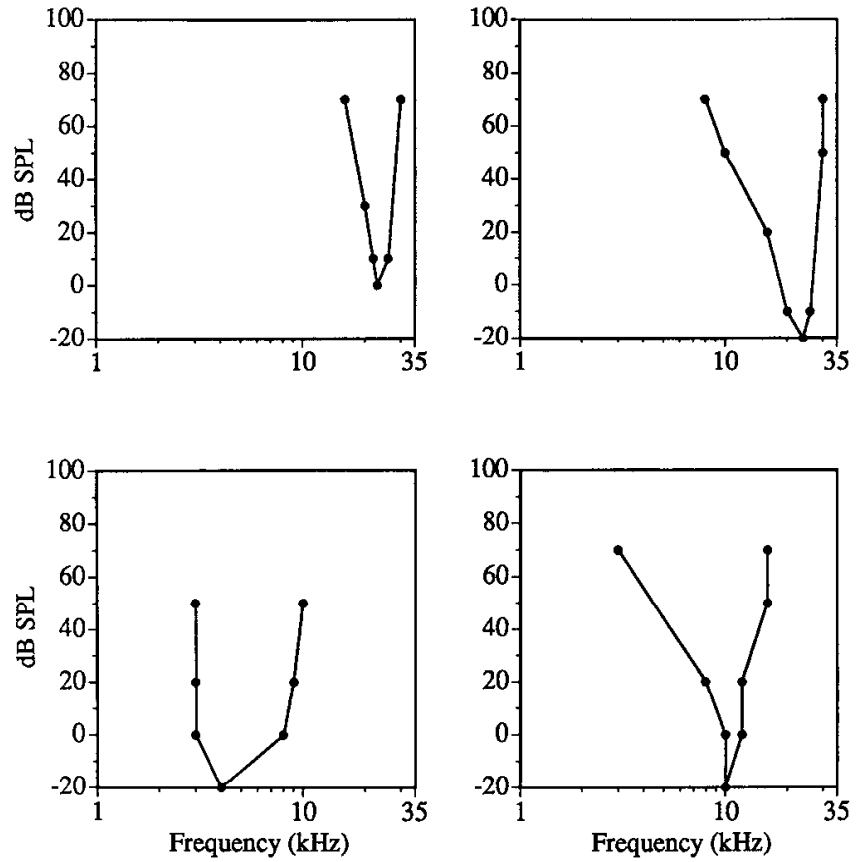
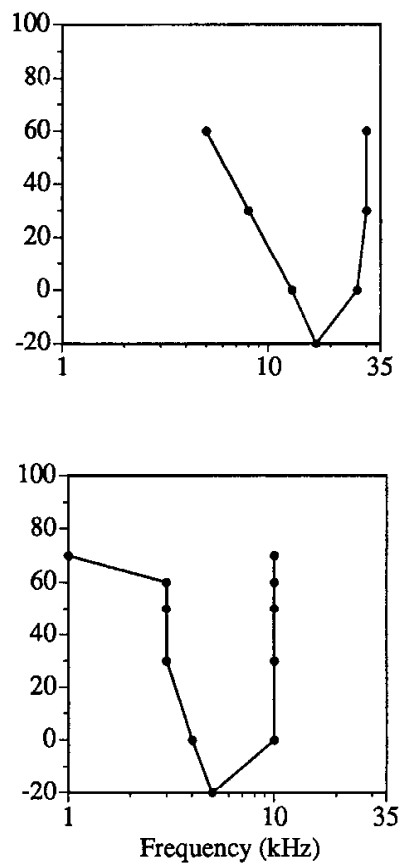

Figure 10. Tuning curves for six tuned neurons located in MGv. See Figure 4 for explanation of luning curve construction. Compare with tuning curves from AL (Fig. 4) and STR (Fig. 9). 
on responses evoked by complex sensory stimuli with social or biological significance (see introductory remarks). With such stimuli, it is difficult to know whether the units are driven by component features or instead by some more global, objectlevel (configural) property of the stimulus. O'Keefe and Bouma (1969) reported that some neurons in the cat amygdala that responded strongly to complex acoustic stimuli (bird calls) did not respond to tones. Few details were given as to the frequencies and intensities of the tones tested. Although the responses of neurons to tones are difficult to evaluate in the absence of proper frequency receptive field analyses, observations of this type have been used to justify the interpretation of responses to complex stimuli in terms of high-level stimulus properties. The present findings, together with the results of several other studies, show that amygdala neurons do respond to tones (Brown and Buchwald, 1973; Le Gal La Salle and Ben-Ari, 1981; Pascoe and Kapp, 1985). In auditory cortex, responses to some (Phillips et al., 1985) but not all (Newman and Wollberg, 1973; Winter and Funkenstein, 1973) complex sounds are in part predictable by the response area of the neuron, as determined by responses to individual tones (Aitkin, 1990). Given that some amygdala neurons have fairly restricted response areas, it is possible that responses to complex sounds by amygdala neurons may in part reflect responses to simpler stimulus properties. At a minimum, the frequency receptive field findings argue that responses to complex stimuli should be cautiously interpreted.

An important consideration in comparing results from different studies is the region of the amygdala recorded from. AL receives most of the direct sensory inputs from areas of the cortex and thalamus (see introductory remarks). Our recordings in AL identified some cells with restricted receptive fields, especially in the dorsal AL. Recordings in other amygdala regions are likely to have broader receptive fields since these areas are farther removed from the sensory system. Past recording studies of the amygdala, with the exception of the work of Le Gal La Salle and Ben-Ari (1981), have not focused on recordings from AL. It is possible that additional convergence across the frequency domain occurs in amygdaloid regions receiving efferents from AL. This could perhaps account in part for complex stimulus properties of cells in these other areas, provided that such responses turn out to not be driven by simpler stimulus properties.

The picture of AL that emerges from these data is that of a structure with a neural architecture designed to respond to acoustic events with a wide range of response characteristics, many of which are readily interpreted in terms of the amygdala's role in fear-related behaviors (Davis et al., 1987; LeDoux, 1987, 1990; Kapp et al., 1990; Panksepp et al., 1991). Rapidly habituating cells may be involved in the detection of novel or changing patterns of stimulation. Novelty and change are important triggers of fear (Gray, 1987). Other cells respond indiscriminantly to acoustic events and may play some role in generally "arousing" AL neurons in preparation for auditory processing, raising the net excitatory level of this tightly interconnected structure (McDonald, 1984). Cells selectively tuned to narrow ranges of high frequencies may allow the amygdala to respond to ultrasonic, biologically relevant events, such as high-frequency distress calls. Recent studies, for example, have shown that adult rats produce ultrasounds in the range of 18$27 \mathrm{kHz}$ when exposed to a predator (Blanchard et al., 1991). Finally, the insensitivity of AL neurons to low levels of auditory stimulation may allow the amygdala to attend selectively to "loud" events. It is easy to imagine how this might be of value to a system involved in processing threatening stimuli. Stimulus intensity is a clue to stimulus distance (other things being equal the louder of two stimuli is likely to be the closer) and proximal stimuli are of more immediate threat than distal stimuli.

The foregoing has emphasized the "hard-wired" aspects of amygdala function. However, the amygdala is also importantly involved in emotional learning (e.g., Davis et al., 1987; Kapp et al., 1990; LeDoux, 1990; Miserendino et al., 1990) and the sensory response properties observed in this study could be related to learning processes. Learning could involve a lowering of the threshold for a given frequency range that is associated in a temporally specific manner with a biologically significant event (an unconditioned stimulus in language of conditioning). That AL neurons exhibit plasticity has been shown in conditioning studies (Le Gal La Salle and Ben-Ari, 1981) and in studies of synaptic plasticity (Chapman and Brown, 1988; Clugnet and LeDoux, 1990). What is needed is an analysis of the effects of learning on frequency receptive field properties of AL neurons, such as has been performed by Weinberger's group on neurons in the auditory system (e.g., Weinberger et al., 1990).

Although we have focused on frequency specificity in response to tones, many other acoustic features remain to be analyzed in amygdala neurons. The fact that only a small proportion of cells were classified as relatively tuned does not mean that the remaining cells are acoustically uninteresting.

In conclusion, we report that (1) many neurons in $\mathrm{AL}$ and STR are responsive to broad-band acoustic stimuli, (2) some of the acoustically responsive neurons have relatively restrictive frequency receptive fields while others are acoustically responsive but untuned with respect to frequency, (3) the relatively tuned cells are not as narrowly tuned as cells in the tonotopically organized MGv, and (4) the relatively tuned cells have higher thresholds than cells in MGv. These findings show that brain areas, such as AL and STR, connected with but outside the normal boundaries of primary sensory systems, maintain sensory tuning properties. The information processing functions of such areas might therefore be fruitfully approached as direct extensions of sensory afferent structures.

\section{References}

Aggleton JP, Burton MJ, Passingham RE (1980) Cortical and subcortical afferents to the amygdala of the rhesus monkey (Macaca mulatta). Brain Res 190:347-368.

Aitkin LM (1990) The auditory cortex. Bristol, UK: Chapman and Hall.

Amaral DG (1987) Memory: anatomical organization of candidate brain regions. In: Handbook of physiology, Sec 1, The nervous system, Vol V, Higher functions of the brain (Plum F, ed), pp 211-294. Bethesda, MD: American Physiological Society.

Blanchard RJ, Weiss S, Agullana R, Flores T, Blanchard DC (1991) Antipredator ultrasounds: sex differences and drug effects. Soc Neurosci Abstr 17:878.

Brothers L, Ring B, Kling A (1990) Response of neurons in the macaque amygdala to complex social stimuli. Behav Brain Res 41:199213.

Brown KA, Buchwald JS (1973) Acoustic responses and plasticity of limbic units in cats. Exp Neurol 40:608-631.

Calford MB (1983) The parcellation of the medial geniculate body of the cat defined by the auditory response properties of single units. $J$ Neurosci 3:2350-2365.

Calford MB, Aitkin LM (1983) Ascending projections to the medial geniculate body of the cat: evidence for multiple, parallel auditory pathways through thalamus. J Neurosci 3:2365-2380.

Calford MB, Webster WR (1981) Auditory representation within principal division of cat medial geniculate body: an electrophysiological study. J Neurophysiol 45:1013-1028. 
Chapman PF, Brown TH (1988) Long-term potentiation in amygdala brain slices. Soc Neurosci Abstr 14:566.

Clugnet MC, LeDoux JE (1990) Synaptic plasticity in fear conditioning circuits: induction of LTP in the lateral nucleus of the amygdala by stimulation of the medial geniculate body. J Neurosci 10:2818-2824.

Clugnet MC, LeDoux JE, Morrison SF (1990) Unit responses evoked in the amygdala and striatum by electrical stimulation of the medial geniculate body. J Neurosci 10:1055-1061.

Davis M, Hitchcock JM, Rosen JB (1987) Anxiety and the amygdala: pharmacological and anatomical analysis of the fear-potentiated startle paradigm. In: The psychology of learning and motivation (Bower GH, ed), vol 21, pp 263-305. San Diego: Academic.

Fuster JM, Uyeda AA (1971) Reactivity of limbic neurons of the monkey to appetitive and aversive signals. Electroencephalogr Clin Neurophysiol 30:281-293.

Geschwind N (1965) The disconnexion syndromes in animals and man, part I. Brain 88:237-294.

Gloor P (1960) Amygdala. In: Handbook of physiology: neurophysiology, Vol II (Field J, Magoun HW, Hall VE, eds), pp 1395-1420. Washington, DC: American Physiological Society.

Gray JA (1987) The psychology of fear and stress. New York: Cambridge UP.

Herzog AG, Van Hoesen GW (1975) Temporal neocortical afferent connections to the amygdala in the rhesus monkey. Brain Res 115: $57-69$.

Jacobs BL, McGinty DJ (1972) Participation of the amygdala in complex stimulus recognition and behavioral inhibition: evidence from unit studies. Brain Res 36:431-436.

Jones B, Mishkin M (1972) Limbic lesions and the problem of stimulus-reinforcement associations. Exp Neurol 36:362-377.

Jones FG, Powell TPS (1970) An anatomical study of converging sensory pathways within the cerebral cortex of the monkey. Brain 93: 793-820.

Kapp BS, Wilson A, Pascoe J, Supple W, Whalen PJ (1990) A neuroanatomical systems analysis of conditioned bradycardia in the rabbit. In: Learning and computational neuroscience: foundations of adaptive networks (Gabriel M, Moore J, eds), pp 53-90. Cambridge, MA: MIT Press.

Kemp JM, Powell TPS (1970) The corticostriate projection in the monkey. Brain 93:525-546.

LeDoux JE (1987) Emotion. In: Handbook of physiology, Sec 1, The nervous system, Vol V, Higher functions of the brain (Plum F, ed), pp 419-460. Bethesda, MD: American Physiological Society.

LeDoux JE (1990) Information flow from sensation to emotion: plasticity in the neural computation of stimulus value. In: Learning and computational neuroscience (Gabriel $\mathrm{M}$, Moore $\mathrm{J}$, eds), pp 3-51. Cambridge, MA: MIT Press.

LeDoux JE, Ruggiero DA, Reis DJ (1985) Projections to the subcortical forebrain from anatomically defined regions of the medial geniculate body in the rat. J Comp Neurol 242:182-213.

LeDoux JE, Farb CF, Ruggiero DA (1990a) Topographic organization of neurons in the acoustic thalamus that project to the amygdala. $J$ Neurosci 10:1043-1054.

LeDoux JE, Cicchetti P, Xagoraris A, Romanski LM (1990b) The lateral amygdaloid nucleus: sensory interface of the amygdala in fear conditioning. J Neurosci 10:1062-1069.

LeDoux JE, Farb C, Romanski L (1991) Overlapping projections to the amygdala and striatum from auditory processing areas of the thalamus and cortex. Neurosci Lett 134:139-144.

Le Gal La Salle G, Ben-Ari Y (1981) Unit activity in the amygdaloid complex: a review. In: The amygdaloid complex (Ben-Ari Y, ed), pp 227-237. New York: Elscvier/North-Holland Biomedical.

McDonald AJ (1984) Neuronal organization of the lateral and basolateral amygdaloid nuclei in the rat. J Comp Neurol 222:589-606.

Miserendino MJD, Sananes CB, Melia KR, Davis M (1990) Blocking of acquisition but not expression of conditioned fear-potentiated starthe by NMDA antagonists in the amygdala. Nature 345:716-718.

Mishkin M, Aggleton J (1981) Multiple functional contributions of the amygdala in the monkey. In: The amygdaloid complex (Ben-Ari Y, ed), pp 409-420. Amsterdam: Elsevier/North-Holland Biomedical.

Moller AR (1983) Auditory physiology. New York: Academic.

Morest DK (1975) Structural organization of the auditory pathways. In: The nervous system, Vol 3: Human communication and its disorders (Tower DB, ed), pp 19-29. New York: Raven.
Newman JD, Wollberg Z (1973) Multiple coding of species-specific vocalizations in the auditory cortex of squirrel monkeys. Brain Res $54: 287-304$.

O'Keefe J, Bouma H (1969) Complex sensory properties of certain amygdala units in the freely moving cat. Exp Neurol 23:384-398.

Ono T, Nishijo H, Nakamura K, Tamura R, Tabuchi E (1988) Role of amygdala and hypothalamic neurons in emotion and behavior. In: Biowarning system in the brain (Takagi $\mathrm{H}$, Oomura $\mathrm{Y}$, Ito $\mathrm{M}$, Otsuka M, eds), pp 309-331. Tokyo: University of Tokyo.

Ottersen OP (1982) Connections of the amygdala of the rat. IV: Corticoamygdaloid and intraamygdaloid connections as studied with axonal transport of horseradish peroxidase. J Comp Neurol 205:30-48.

Pandya DN, Kuypers HGJM (1969) Cortico-cortical connections in the rhesus monkey. Brain Res 13:13-36.

Panksepp J, Sacks DS, Crepau LJ, Abbot BB (1991) The psycho- and neurobiology of fear systems in the brain. In: Fear, avoidance, and phobias (Denny MR, ed), pp 7-59. Hillsdale, NJ: Earlbaum.

Pascoe JP, Kapp BS (1985) Electrophysiological characteristics of amygdaloid central nucleus neurons during Pavlovian fear conditioning in the rabbit. Behav Brain Res 16:117-133.

Paxinos G, Watson C (1986) The rat brain in stereotaxic coordinates. Sydney: Academic.

Phillips DP, Mendelson JR, Cynader MS, Douglas RM (1985) Responses of single neurones in cat auditory cortex to time-varying stimuli: frequency-modulated tones of narrow excursion. Exp Brain Res 58:443-454.

Redies H, Brandner S, Creutzfeldt OD (1989) Anatomy of the auditory thalamocortical system of the guinea pig. J Comp Neurol 282:489511.

Rolls ET (1986) A theory of emotion, and its application to understanding the neural basis of emotion. In: Emotions: neural and chemical control (Oomur Y, ed), pp 325-344. Tokyo: Japan Scientific Societies.

Russchen FT (1982) Amygdalopetal projections in the cat. I. Cortical afferent connections. A study with retrograde and anterograde tracing techniques. J Comp Neurol 206:159-179.

Sanghera MK, Rolls ET, Roper-Hall A (1979) Visual responses of neurons in the dorsolateral amygdala of the alert monkey. Exp Neurol 63:610-626.

Schutze I, Knuepfer MM, Eismann A, Stumpf H, Stock G (1987) Sensory input to single neurons in the amygdala of the cat. Exp Neurol 97:499-515.

Turner BH, Herkenham M (1991) Thalamoamygdaloid projections in the rat: a test of the amygdala's role in sensory processing. J Comp Neurol 313:295-325

Turner BH, Mishkin M, Knapp M (1980) Organization of the amygdalopetal projections from modality-specific cortical association areas in the monkcy. J Comp Neurol 191:515-543.

Van Hoesen GW (1982) The parahippocampal gyrus: new observations regarding its cortical connections in the monkey. Trends Neurosci 5:345-350.

Veening JG (1978) Subcortical afferents of the amygdaloid complex in the rat: an HRP study. Neurosci Lett 8:197-202.

Weinberger N, Ashe J, Metherate R, McKenna T, Diamond D, Bakin J, Lennartz R, Cassady J (1990) Neural adaptive information processing: a preliminary model of receptive-field plasticity in auditory cortex during Pavlovian conditioning. In: Learning and computational neuroscience: foundations of adaptive networks (Gabriel $\mathrm{M}$, Moore J, eds), pp 91-138. Cambridge, MA: MIT Press.

Weiskrantz L (1956) Behavioral changes associated with ablation of the amygdaloid complex in monkeys. J Comp Physiol Psychol 49: 381-391.

Whitlock DG, Nauta WJH (1956) Subcortical projections from the temporal neocortex in Macaca mulatta. J Comp Neurol 106:183212.

Winer JA, Morest DK (1983) The medial division of the medial geniculate body of the cat: implications for thalamic organization. J Neurosci 3:2629-2651.

Winter P, Funkenstein HH (1973) The effect of species-specific vocalization on the discharge of auditory cortical cells in the awake squirrel monkey (Saimiri sciureus). Exp Brain Res 18:489-504.

Yeterian EH, Van Hoesen GW (1978) Cortico-striate projections in the rhesus monkey: the organization of certain corticocaudate connections. Brain Res 139:43-63. 